\title{
Postural and Load Distribution Asymmetries in Preschoolers
}

\author{
Assimetrias Postural e de Distribuição de Carga em Pré-escolares
}

\author{
Paulysnara de Oliveira Almeida ${ }^{1}$, Geisyani Francisca Gomes Prudente ${ }^{1}$, Fabiane Elpídio de \\ Sá1, Lidiane Andréa Oliveira Lima ${ }^{1}$, Fabianna Resende Jesus-Moraleida ${ }^{1}$, Kátia Virginia \\ Viana-Cardoso ${ }^{1^{*}}$
}

ORIGINAL ARTICLE | ARTIGO ORIGINAL

\begin{abstract}
The aim of the study was to investigate the postural and load distribution symmetries in preschool children. The sample consisted of 67 preschool children with a median age of $54.00 \pm 5.06$ months. Postural parameters such as the horizontal alignment of the head, the acromion and Antero Superior Iliac Spines (ASIS), the angles between the acromial and ASIS, frontal, $\mathrm{Q}$, knee and ankle and horizontal asymmetry of the scapula in relation to T3 were evaluated by photogrammetry. The baropodometry was used to identify the distribution of plantar pressure, while the medial arch of the foot was analyzed by photographic image. The median, standard deviation and the symmetry ratio were calculated for each parameter considered symmetry values greater than $90 \%$. The Pearson's or Spearman's correlation were used between the parameters analyzed. There was asymmetric for postural and load distribution parameters for both genders and a null correlation between the symmetry of the surface and foot morphology and negative weak correlation significant between of the load foot and the front angle of the lower limb symmetries. The presence of asymmetries, postural and/or of load distribution, observed in early childhood suggest the importance of monitoring the postural and foot load parameters in the long term, preventing future postural and biomechanical alterations.
\end{abstract}

Keywords: Child, Preschool, Posture.

RESUMO

O objetivo do estudo foi investigar a simetria postural e de distribuição de carga em crianças pré-escolares. A amostra foi composta de 67 crianças pré-escolares. Parâmetros posturais como: os alinhamentos horizontais da cabeça, do acrômio e das Espinhas Ilíacas Antero Superiores (EIAS), os ângulos entre os acrômios e as EIAS, frontal, Q, do joelho e do tornozelo e a assimetria horizontal da escápula em relação à T3 foram avaliados por fotogrametria. Baropodometria foi utilizada para identificar a distribuição da pressão plantar, enquanto o arco medial do pé foi analisado por fotografia. A mediana, o desvio padrão e a razão de simetria foram calculadas para cada parâmetro, sendo considerado simetria valores superiores a $90 \%$. Correlação foi realizada entre os parâmetros analisados. Houve distribuição assimétrica para os parâmetros posturais e de distribuição de carga e uma correlação fraca e significativa entre a simetria da superfície e morfologia podal e entre a simetria da carga podal e do ângulo frontal do membro inferior. A presença de assimetrias, postural e de distribuição de carga observadas na primeira infância sugerem a importância de se monitorar os parâmetros posturais e de carga podal a longo prazo, a fim de prevenir alterações posturais e biomecânicas futuras

Palavras-chave: Criança, Pré-escolar, Postura.

Manuscript received at June 22 $2^{\text {nd }} 2014$; Accepted at December $17^{\text {th }} 2014$

${ }^{1}$ Universidade Federal do Ceará, Brasil

* Corresponding author. Dr. José Lourenço, 3308, 1102 apt, Joaquim Távora, Fortaleza, Ceará, Brazil, telephone mumber:+5585997663814 E-mail: kvvc2004@yahoo.com.br 


\section{INTRODUCTION}

Posture is defined as the positioning of body parts that are capable of maintaining proper body symmetry without discomfort or difficulty during a given time, during which the musculoskeletal structures are balanced and are therefore less likely to incur injuries or deformities (Van Maanen, Zonnenberg, Elvers, \& Oostendorp, 1996; Watson \& Mac Donncha, 2000). Body symmetry favors neuropsychomotor development, allowing a coordinated, functional, and energetically economic movement (Rochat \& Goubet, 1995).

Postural misalignment or asymmetry is often observed in infancy and can be idiopathic or due to different etiologies such as congenital torticollis, congenital clubfoot, congenital hip dislocation, and plagiocephaly (Behrman, Kliegman, \& Jenson, 2000; Nissinen, Heliövaara, Tallroth, \& Poussa, 1989). Juskeliene, Magnus, Bakketeig, Dailidiene, and Jurkuvenas (1996)) revealed that almost half (46.9\%) of the children, aged 6 to 7 years, whom they evaluated in their study, had postural asymmetry.

Some risk factors may be associated with these asymmetries in childhood, such as low family economic status, lack of physical activity, and deprivation of psychic stimuli (Kratěnová, ŽEjglicová, Malý, \& Filipová, 2007; Latalski et al., 2013).

Early diagnosis and monitoring of postural asymmetries in childhood are important for the prevention of plagiocephaly, dislocation of the temporomandibular joint (St John, Mulliken, Kaban, \& Padwa, 2002), strabismus, torticollis (Cheng \& Au, 1994), asymmetric displacement of the occipital condyles and atlanto-occipital joints, progressive scoliosis (McMaster, 1983), malformations of the feet and hips, and gait disorders (Behrman et al., 2000). Among the various assessment methods of postural asymmetry, photogrammetry is commonly used because it is considered as a cheap, simple, and reliable resource for assessing measurements in adults and children (Santos, Silva, Sanada, \& Alves, 2009).

The first 5 years of life, called "early childhood," are characterized by the dynamic processes of development and maturation of the central nervous system (Peskin, Spitzer, Peleg, \& Zalsman, 2011). During this period, the presence of postural asymmetries may cause future malfunctions, which in turn cause the adaptations of the locomotor system to alter the biomechanical conditions of the individual. Thus, these asymmetries can result in excessive loading of the heel and contribute to problems in growth and development in childhood (Matsuda \& Demura, 2013).

Plantar pressure measurement obtained by using baropodometry is normally used to determine the specific load characteristics of the plantar region of the foot (Stebbins et al., 2005). The study of plantar pressure distribution allows for the assessment of biomechanical posture, which aids in the diagnosis and early treatment of various musculoskeletal disorders (Cheng \& $\mathrm{Au}, 1994)$. However, most studies do not address postural asymmetry at the early stage of child development (Juskeliene et al., 1996; Kellis, 2001; Matsuda \& Demura, 2013). Thus, postural symmetry and load distribution are not commonly assessed in early childhood, although they may contribute to the development of strategies that may minimize long-term biomechanical changes.

Accordingly, this study aimed to investigate postural symmetry and load distribution in preschool children, and verify how these are affected by sex. We hypothesized that postural asymmetry is attained at preschool age and differs between sexes.

\section{METHOD}

This is a quantitative, cross-sectional study.

\section{Participants}

We evaluated 67 healthy children, including 36 boys (median age, $54.00 \pm 4.22$ months) and 31 girls (55.00 \pm 5.91 months), who were attending a charity nursery in the city of Fortaleza, Brazil.

The exclusion criteria for this study were the presence of pathologies in the feet or other disorders that lead to potential gait limitations, such as previous fracture of any body part that 
may have interfered with the development of posture, genetic diseases or musculoskeletal disorders, or neuromuscular or degenerative diseases.

Parents or guardians provided informed consent, and the study was approved by the ethics committee of the Federal University of Ceará (protocol no. 089/11).

\section{Instruments}

Anthropometric data were assessed by using an anthropometric scale (Welmy, Santa Bárbara d'Oeste, SP, Brazil) with a precision of $100 \mathrm{~g}$ in weight and $0.5 \mathrm{~cm}$ in height.

A camera (Sony Cyber-Shot DSC-P93, Tokyo, Japan) attached to a tripod was used to obtain the images. These images were then submitted to a photogrammetric analysis through the Postural Analysis Software (SAPO, São Paulo, Brazil) available at a public domain (http://puig.pro.br/sapo/) (Ferreira, Duarte, Maldonado, Burke, \& Marques, 2010).

An electronic baropodometer (Diagnostic Support-DIASU, Rome, Italy) composed of a modular platform with 4800 active resistive sensors in a $320-\mathrm{cm}$ array was used for the measurement of plantar pressure distribution. The results were presented using a color scale, which is proportional to the pressure exerted on a given area of the detector, where brown shades represent lower pressures and red shades represent higher pressures. The analysis was performed by using the Milletrix software that provides a description and quantification of the distribution of maximum and average surface and load pressures at rest (Bruner et al., 2009). The following parameters were calculated: maximum pressure $\left(\mathrm{g} / \mathrm{cm}^{2}\right)$, average pressure $\left(\mathrm{g} / \mathrm{cm}^{2}\right)$, contact surface area $\left(\mathrm{cm}^{2}\right)$, and load $(\mathrm{kg})$.

\section{Procedures}

The assessments were conducted at the Laboratory for Analysis of Human Movement. The environment where the tests were performed was prepared so that the children felt as comfortable and spontaneous as possible.

For the anthropometric, postural and baropodometric assessments, all the children remained barefoot, with minimal clothing, to allow for a good visualization of their postures.

Initially, the height $(\mathrm{m})$ and body mass $(\mathrm{kg})$ of the children were measured by using an anthropometric scale. Body mass index (BMI) was calculated by dividing the mass by the height squared.

Prior to the original study, the inter-examiner reliability was tested. Prior to the initiation of the study, the postural photogrammetric measurements of 13 children were assessed by three raters who were familiar with the SAPO program. The images obtained were subsequently delivered to the evaluators, with the following guidelines: calibrate the picture, score points according to the protocol, generate the analysis report, and export results to Excel $\left(\right.$ Microsoft Office ${ }^{\circledR}$ ). For the analysis of intraexaminer reliability, postural photogrammetry was performed twice at an interval of 1 week, by a single evaluator.

For photogrammetric analysis, markers made with half of 15-mm Styrofoam balls were placed on the following anatomical points in the participants' bodies: glabella, earlobes, chin, acromions, manubrium of the sternum, inferior angle of the scapula, spinous processes of $\mathrm{C} 7, \mathrm{~T} 6$ and $\mathrm{T} 12$, anterior superior and upper posterior iliac spines, greater trochanter of the femur, knee joint lines, anterior tuberosity of the tibia, malleolus, and calcaneus.

The children remained positioned on foot to obtain postural images in the sagittal and frontal planes (Figure 1). For this, a digital camera was positioned on a tripod (height, $1.63 \mathrm{~m}$ ) at $90^{\circ}$ and $1.9 \mathrm{~m}$ from the participant. The camera was adjusted for image enlargement to allow approximately $0.5-\mathrm{m}$ free space above and below the subject to minimize any distortion of image edges (Ferreira et al., 2010).

A plumb line marked with two Styrofoam balls at a distance of $0.5 \mathrm{~m}$ was used for vertical calibration of the software, which obtained the number of pixels spanning the plumb line, which the program converts into centimeters, storing the result as an internal variable (Figure 2). Thus, the following variables were analyzed on photographic images by using the SAPO software: horizontal head alignment, horizontal 
alignment of the acromion, horizontal anterior superior iliac spine (ASIS) alignment, angle between 2 acromions and 2 ASIS, frontal angle of the right and left lower limbs, right and left $\mathrm{Q}$ angles, horizontal asymmetry of the scapula relative to $\mathrm{T} 3$, right and left knee angles, and right and left ankle angles (Ferreira et al., 2010).

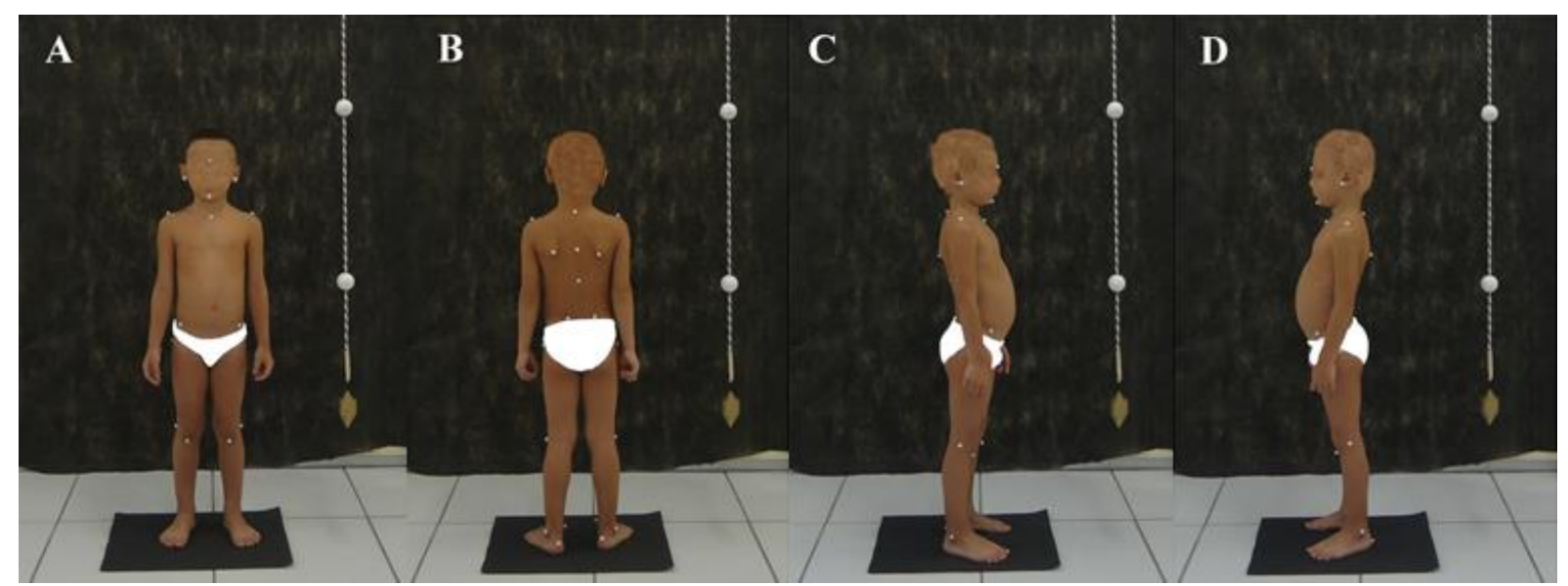

Figure 1. Positioning of children to obtain the images for photogrammetry. Panel A - Anterior frontal plane, panel B - Posterior frontal plane, panel C - Right sagittal plane and panel D - Left sagittal plane.
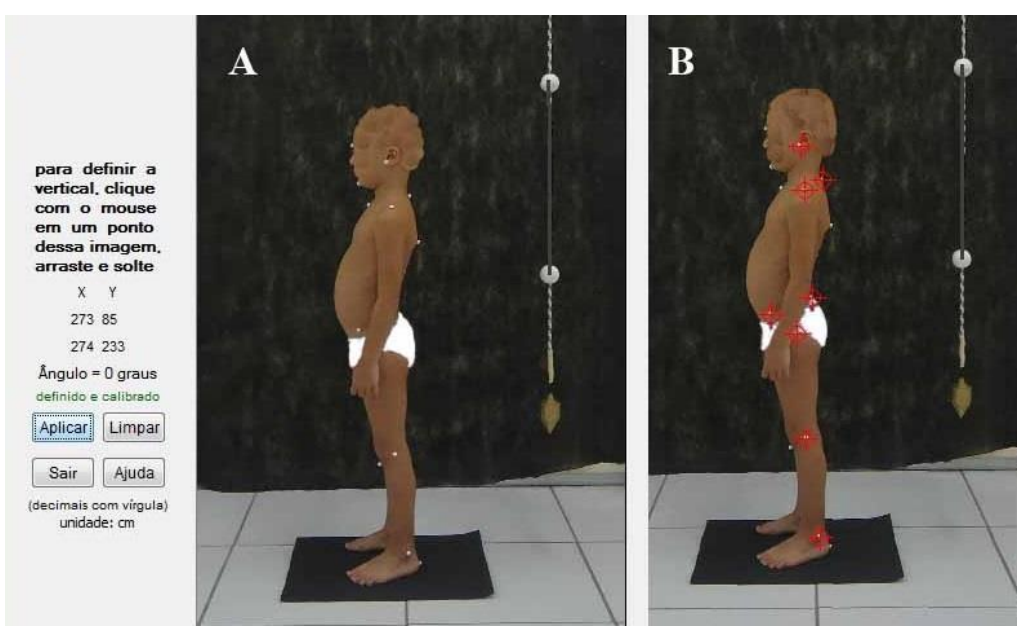

Figure 2. Calibration (Panel A) and scoring (Panel B) for the analysis of images for photogrammetry using SAPO (Postural Analysis Software).

Thereafter, each participant stood for 5-10 seconds on the electronic baropodometry platform in a postural resting position, with arms at their sides, feet slightly apart, being encouraged to stay as relaxed as possible in order to not consciously affect posture during data acquisition. (Filippin, Barbosa, Sacco, \& Lobo da Costa, 2007) (Figure 3).

Finally, foot morphology was assessed by using a single photographic image of both feet while the participant stood, with relief of the bilateral weight, over a podograph. The Staheli Arch Index (SAI) was used for evaluation of the medial longitudinal arch of the footprints by calculating the ratio between the width of the medial arch of the foot and the width of the heel (Staheli, Chew, \& Corbett, 1987).

The asymmetries observed during the evaluation of static posture were calculated by determining the ratio between the smallest and largest values (Clark, 2001). This symmetry ratio was adapted from Clark (2001) and determined with the following equation, where $\mathrm{X} 1$ and $\mathrm{X} 2$ are the variables with the highest and lowest values, respectively:

$$
\text { Symmetry Ratio }(\mathrm{SR})=\frac{100 \times X 1}{X 2}
$$



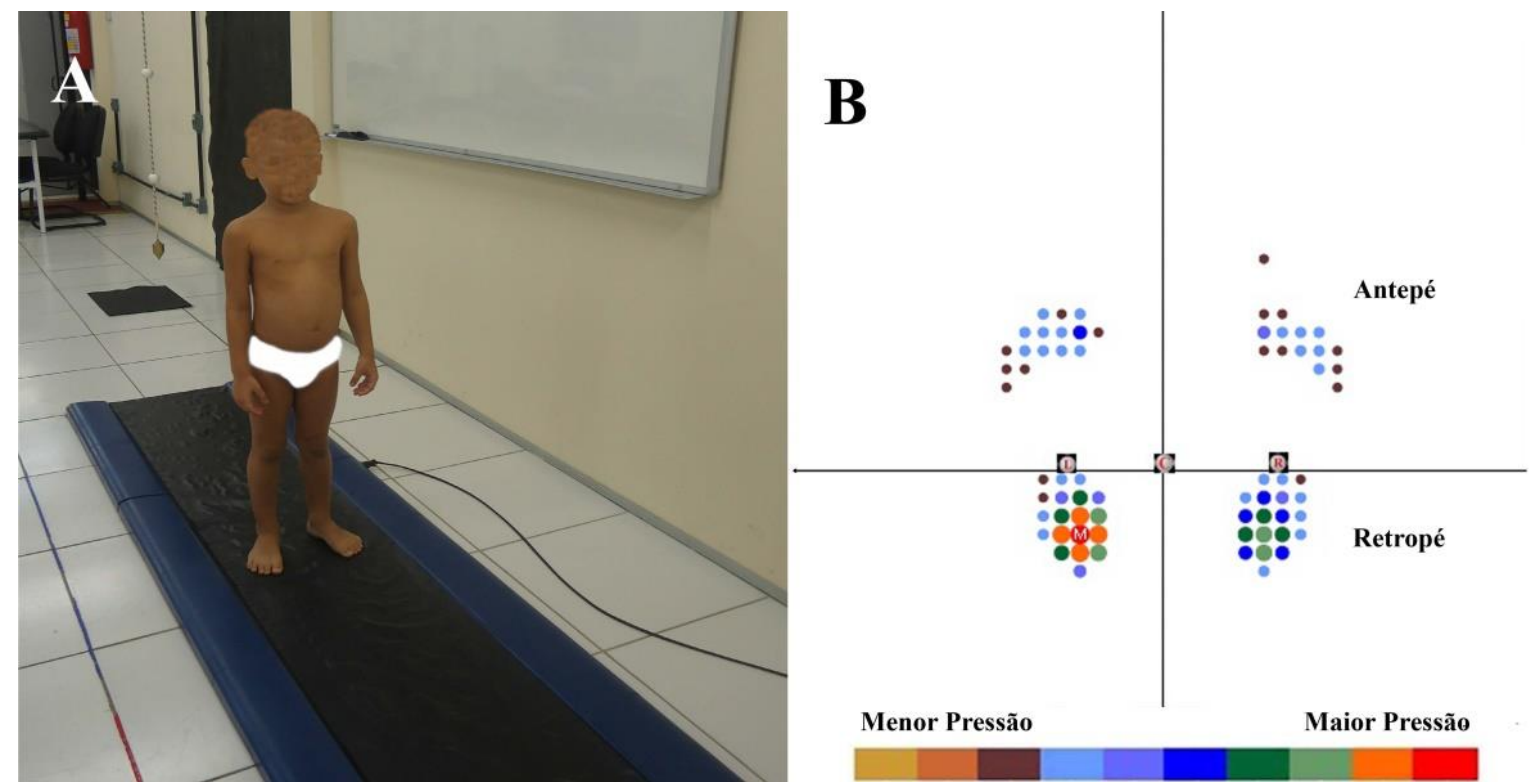

Figure 3. Positioning of children to obtain the plantar pressures. Panel A - Baropodometric examination and panel B - Plantar pressure.

\section{Statistical analysis}

Descriptive statistical and normality tests were performed by using the Sigma Stat statistical software version 3.5 for Windows 3.5 (SPSS Inc. 2007). For data with a normal distribution, Student's $t$ test was used, whereas for data with non-normal distribution, a nonparametric test (Mann-Whitney or Wilcoxon test) was used for comparison between the two groups. A descriptive analysis of the parameters of postural photogrammetry, baropodometry, and the SAI values was performed by calculating the frequency for the variables shown, the symmetry ratio, the coefficient of variation $(\mathrm{CV})$, and the magnitude of effect. CV was defined as the ratio between the standard deviation and the mean $(\mathrm{CV}=\mathrm{SD} / x)$. The magnitude of the effect was calculated by using Cohen's $d$ (Cohen, 1994). Statistical analysis of the inter- and intrarater reliability of photogrammetry was analyzed by using the intraclass correlation coefficient (ICC) index, considering a significance level of $\mathrm{p}$ $<0.05$. An ICC value of 1 indicates that the angle values were identical in the comparisons. ICC values lower than 0.70 were considered not acceptable; those between 0.71 and 0.79 , acceptable; those between 0.80 and 0.89 , very good; and those higher than 0.90 , excellent (Iunes et al., 2005).
Student's $t$ test was used to compare sexes and feet, with the data having a normal distribution. Finally, the Pearson correlation test for parametric data or Spearman coefficient for nonparametric data was used for all the parameters. However, we only described results with relevance correlations. The Spearman $r$ was qualitatively assessed as follows: $r=1$ (perfect correlation), $0.7<\mathrm{r}<0.9$ (strong correlation), $0.4<\mathrm{r}<0.7$ (moderate correlation), $0.2<r<$ 0.4 (weak correlation), and $r=0$ (zero correlation). Pearson $r$ correlations between 0.10 and 0.29 were considered weak, values between 0.30 and 0.49 were considered moderate, and values between 0.50 and 1 were considered as strong. For all the analyses, the level of significance was set at $\mathrm{p}<0.05$.

\section{RESULTS}

\section{Anthropometric data}

Table 1 presents the anthropometric data of the 67 children who comprised the study sample; $53.7 \%$ were boys, and $46.3 \%$ were girls. No significant differences in anthropometric data body mass ( $W=0.96 ; p=0.08$ ) and height ( $W=$ $0.97 ; p=0.34$ ) were observed between the boys and girls.

Moderate and significant positive correlations were observed between BMI and the foot 
loadings on the left and right feet $(r=0.46, \mathrm{p}<$ 0.001 and $r=0.34, p=0.005$, respectively) in the study sample.

\section{Postural photogrammetric parameters}

The categorization of the adopted values and the results obtained demonstrate an excellent inter-rater reliability (ICC $>0.90$ ) for 10 variables $(34.4 \%)$, good agreement $(0.80>$ ICC $>0.89$ ) for 6 variables (20.7\%), acceptable agreement $(0.70>$ ICC $>0.79)$ for 3 variables $(10.3 \%)$, and unacceptable (ICC $<0.70$ ) for 10 variables $(34.4 \%)$. The horizontal alignment of the head with the left and right $\mathrm{C} 7$, the vertical alignment of the head with the left and right acromions, the vertical alignment of the left and right torsos, the vertical angles of the left and right body, the horizontal alignment of the left and right pelvis, the difference in the lengths of the lower limbs, the left and right hip angles (trunk/thigh), the horizontal alignment of the tibial tuberosity, and the left and right leg/hindfoot angles showed low reliability and were thus excluded from the main analysis.

Table 2 displays the median and standard deviation values, besides the symmetry ratios of the variables analyzed. The parameters analyzed showed no significant difference between the lower limbs, and we found a small effect size of the frontal angle between the left lower limb and right lower limb of the boys ( $d$ Cohen $=-0.05$; $p=0.71$ ) and of the girls ( $d$ Cohen $=-0.28 ; p=$ $0.27)$; a small effect size of the $Q$ angle between the lower limbs of the boys ( $d$ Cohen $=-0.01 ; p=$ 0.79 ) and of the girls ( $d$ Cohen $=0.13 ; p=0.60)$; a small effect size of the knee angle between the lower limbs of the boys ( $d$ Cohen $=-0.16$; $p=$ 0.49 ) and of the girls ( $d$ Cohen $=0.24 ; p=0.27$ ); and we found also a small effect size of the ankle angle between the left lower limb and right lower limb of the boys ( $d$ Cohen $=0.06 ; p=0.78$ ) and of the girls ( $d$ Cohen $=0.14 ; p=0.57$ ).

The parameters analyzed showed no significant difference between the sexes. With the exception of the SR ankle angle, all the other SR values were lower than $90 \%$, indicating postural asymmetry in the sample. Photogrammetry parameters presented CV with values ranging from $5.9 \%$ to $1999 \%$. The variable with the greatest variation was the horizontal alignment of the head and that with the least variation was the ankle angle.

\section{Baropodometric parameters}

Figure 4 shows the median and standard deviation values of the baropodometric data. The total surface area was $71.0 \pm 78.46 \mathrm{~cm}^{2}$ for boys and $67.0 \pm 33.01 \mathrm{~cm}^{2}$ for girls $(p=0.25)$. The maximum pressure was $467.50 \pm 263.0 \mathrm{~g} / \mathrm{cm}^{2}$ for boys and $595.7 \pm 283.28 \mathrm{~g} / \mathrm{cm}^{2}$ for girls $(p=$ 0.47 ), and the average pressure was $241.9 \pm$ $197.33 \mathrm{~g} / \mathrm{cm}^{2}$ for boys and $211.35 \pm 275.9 \mathrm{~g} / \mathrm{cm}^{2}$ for girls $(p=0.25)$. Total surface $(W=0.57, p$ $<0.001)$, maximum pressure $(W=0.88, p<$ 0.001 ), and average pressure $(W=0.84, p<$ $0.001)$.

Table 1

Distribution of children by age, body weight and height

\begin{tabular}{|c|c|c|c|c|c|}
\hline & \multirow{2}{*}{ Children } & \multicolumn{2}{|c|}{ Sexes } & \multirow{2}{*}{$p$} & \multirow{2}{*}{$d$ Cohen } \\
\hline & & Boys & Girls & & \\
\hline Number & 67 & 36 & 31 & & \\
\hline Age (months) & $55.25(5.06)$ & $54.00(4.22)$ & $55.00(5.91)$ & 0.41 & -0.19 \\
\hline Body mass $(\mathrm{kg})$ & $17.00(2.65)$ & $17.00(2.59)$ & $17.00(2.77)$ & 0.81 & -0.05 \\
\hline Height $(\mathrm{cm})$ & $106.00(4.85)$ & $107.00(3.90)$ & $105.50(5.70)$ & 0.13 & 0.37 \\
\hline $\operatorname{BMI}\left(\mathrm{kg} / \mathrm{m}^{2}\right)$ & $15.34(1.66)$ & $15.20(1.70)$ & $15.40(1.61)$ & 0.42 & 0.20 \\
\hline
\end{tabular}

Note. Standard Deviations appear in parentheses below medians. BMI = Body mass index. 
64 | PO Almeida, GFG Prudente, FE de Sá, LAO Lima, FR Jesus-Moraleida, KV Viana-Cardoso

Table 2

Postural parameters of the preschool children

\begin{tabular}{|c|c|c|c|c|}
\hline Parameters & Boys & Girls & $\mathrm{p}$ & $d$ Cohen \\
\hline Horizontal head alignment $(\mathrm{)})$ & $1.00(3.97)$ & $0.00(4.41)$ & 0.10 & 0.40 \\
\hline Horizontal alignment of the acromion $(\mathcal{})$ & $0.50(3.32)$ & $0.80(3.76)$ & 0.46 & -0.18 \\
\hline Horizontal ASIS alignment $\left({ }^{(}\right)$ & $0.40(4.13)$ & $-0.90(3.59)$ & 0.59 & 0.13 \\
\hline Angle between 2 acromions and 2 ASIS $\left(^{\circ}\right)$ & $-1.40(4.10)$ & $-1.80(4.89)$ & 0.90 & 0.03 \\
\hline \multicolumn{5}{|l|}{ Frontal angle $(\mathcal{O})$} \\
\hline Left lower limb & $-3.70(9.97)$ & $-5.20(3.37)$ & 0.10 & 0.34 \\
\hline Right lower limb & $-3.70(8.97)$ & $-4.30(3.49)$ & 0.33 & -0.30 \\
\hline SR frontal angle (\%) & $59.90(44.45)$ & $60.20(37.47)$ & 0.86 & -0.12 \\
\hline \multicolumn{5}{|l|}{ Q angle } \\
\hline Left lower limb & $11.70(10.36)$ & $16.60(9.73)$ & 0.18 & 0.41 \\
\hline Right lower limb & $12.50(10.03)$ & $16.20(13.48)$ & 0.40 & -0.20 \\
\hline$S R$ Q angle (\%) & $49.50(41.08)$ & $59.50(45.75)$ & 0.62 & 0.04 \\
\hline Horizontal asymmetry of the scapula relative to T3 $\left(^{\circ}\right)$ & $0.00(21.52)$ & $-9.30(25.20)$ & 0.11 & 0.42 \\
\hline \multicolumn{5}{|l|}{ Knee angle $\left({ }^{\circ}\right)$} \\
\hline Left lower limb & $-0.05(9.52)$ & $2.00(7.87)$ & 0.31 & 0.25 \\
\hline Right lower limb & $-0.30(9.02)$ & $-1.10(8.03)$ & 0.55 & 0.14 \\
\hline SR knee angle (\%) & $33.90(53.98)$ & $19.50(48.65)$ & 0.63 & 0.15 \\
\hline \multicolumn{5}{|l|}{ Ankle angle $\left(^{(}\right)$} \\
\hline Left lower limb & $85.20(4.95)$ & $85.80(5.68)$ & 0.58 & -0.13 \\
\hline Right lower limb & $84.90(4.94)$ & $85.00(5.33)$ & 0.88 & 0.05 \\
\hline SR ankle angle (\%) & $95.00(2.65)$ & $94.80(3.97)$ & 0.59 & 0.26 \\
\hline
\end{tabular}

Note. Standard Deviations appear in parentheses below medians. SR = symmetry ratio. ASIS $=$ Antero Superior Iliac Spines.
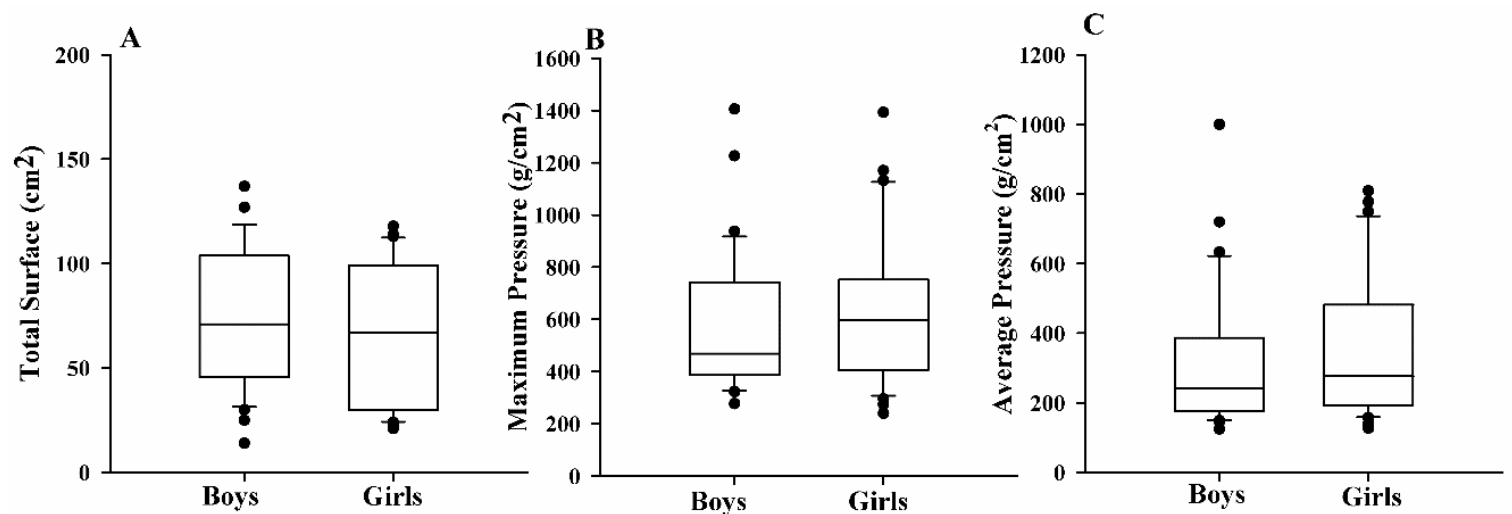

Figure 4. Baropodometric parameters of the feet of the preschool children. Panel A - Total surface ( $\mathrm{cm} 2)$, panel B -Maximum pressure $(\mathrm{g} / \mathrm{cm} 2)$ and panel C - Average pressure $(\mathrm{g} / \mathrm{cm} 2)$. Data expressed as median \pm standard deviation.

Table 3

Barometric parameters for each foot of preschool children

\begin{tabular}{lccc}
\hline Parameters & Boys & Girls & $d$ Cohen \\
\hline \multicolumn{2}{c}{ Contact surface area $\left(\mathrm{cm}^{2}\right)$} & & \\
$\quad$ Left foot & $36.00(17.17)$ & $28.00(17.83)$ & 0.21 \\
Right foot & $41.00(18.20)$ & $32.00(16.61)$ & -0.46 \\
\hline $\begin{array}{l}\text { SR Contact } \\
\text { surface area (\%) }\end{array}$ & $87.70(19.25)$ & $82.20(20.94)$ & 0.16 \\
\hline Load (kg) & & & \\
$\quad$ Left foot & $8.80(2.19)$ & $8.30(2.83)$ & 0.04 \\
Right foot & $8.80(2.70)$ & $8.20(2.70)$ & 0.22 \\
\hline SR Load (\%) & $74.00(18.90)$ & $73.20(23.47)$ & -0.06
\end{tabular}

Note. Standard Deviations appear in parentheses below medians. $\mathrm{SR}=$ symmetry ratio.
Table 3 shows the median and standard deviation values, and symmetry ratios of the variables for each foot of the children aged 4-5 years. No statistical differences were observed between the surface of the left and right feet, or between feet loading. We found a little negative effect size of the contact surface area between the left foot and right foot of the boys ( $d$ Cohen $=$ $0.16 ; p=0.71)$ and of the girls ( $d$ Cohen $=-0.07$; $p=0.34$ ) and we found also a little positive effect size of the load between the left foot and right foot of the boys ( $d$ Cohen $=0.12 ; p=0.60$ ) and of the girls $(d$ Cohen $=0.54 ; p=0.15)$. 
The surface symmetry ratio was lower than $90 \%$ in $62.7 \%$ of the children $(n=42)$, while the loading symmetry ratios were lower in $79.1 \%$ (n $=53$ ) of the children tested. The baropodometric parameters had CV ranging from $29 \%$ to $82 \%$.

\section{Foot morphology (SAI)}

The median and standard deviation values of the SAI for the left and right feet were $0.74 \pm$ 0.05 and $0.70 \pm 0.05$, respectively, in the girls, and $0.82 \pm 0.05$ and $0.75 \pm 0.05$, respectively, in the boys, with no statistical difference between the feet of the girls and those of the boys ( $p=$ 0.85 and $p=0.99$, respectively; $W=0.04$ and $W=$ -0.03 , respectively). The symmetry ratio of the foot morphology was $86.26 \% \pm 9.49 \%$ for the boys and $83.52 \% \pm 25.88 \%$ for the girls, with no statistically significant difference $(\mathrm{p}=0.74, W=$ $0.34)$. However, the median values were lower than $90 \%$, indicating foot asymmetry. These parameters had CV ranging from $35 \%$ to $38 \%$.

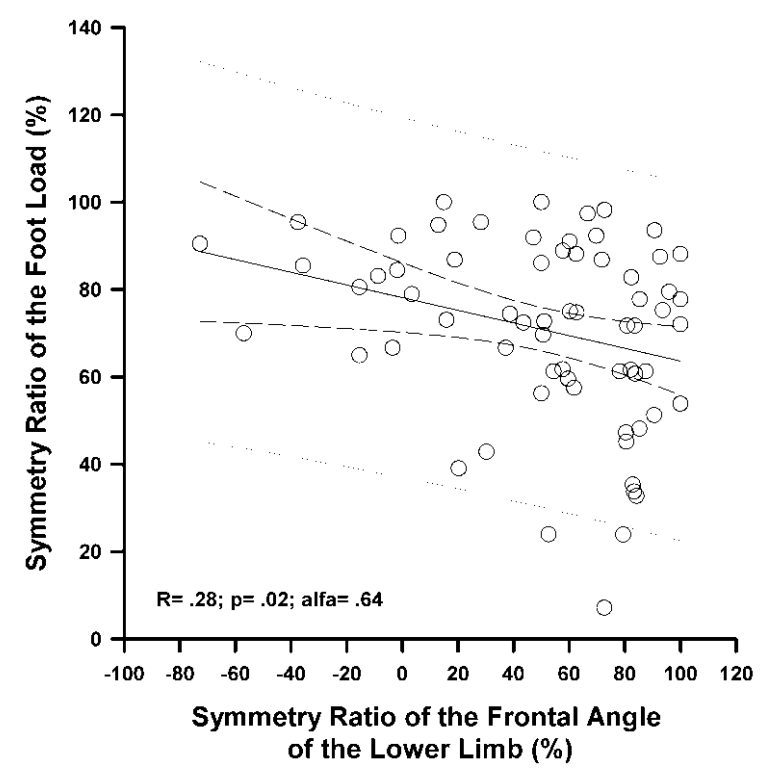

Figure 5. Correlation between symmetries ratios of the foot load and of the frontal angle of the lower limb of the preschool children.

Correlations of postural parameters, foot morphology, and foot loading

To better understand the results, we only described the clinically significant correlations. We found a non significant correlation between the surface RS and the RS of foot morphology ( $r=$ $0.07 ; p=0.57$ ).
We found a weak negative correlation between the load RS and front-angle RS of the lower limbs $(r=-0.28 ; p=0.02$; Figure 5$)$.

\section{DISCUSSION}

The results of this study indicated a postural and foot load distribution asymmetry in the preschool children, which are in agreement with the results obtained in previous studies in children.

van Vlimmeren, Helders, van Adrichem, and Engelbert (2004) reviewed the literature and concluded that postural asymmetry in infancy is a diagnosis with a large spectrum of functionalities and a multifactorial etiology; that no consensus has been reached on its definition, nomenclature, and classification; that data regarding the natural course of postural asymmetry are scarce; and that systematic management of asymmetry is greatly needed in infancy.

Juskeliene et al. (1996) found trunk asymmetry in $46.9 \%$ of children aged $6-7$ years, with a high prevalence similar to that found in our study. The ratio between boys and girls was 1.18 , and the difference between the sexes was significantly different from that in our sample, in which no significant difference was observed between the sexes. These asymmetries were analyzed with different methods by using a symmetrograph and plumb line and evaluating the angle between the seventh cervical vertebra (C7) and lower angles of the scapulae. The discrepancy results may be partially justified by the difference in the instruments used in the studies.

Matsuda and Demura (2013) analyzed plantar pressure in children aged 3.5-6.5 years and concluded that the pressure increases with age due to changes in the shape and formation of the longitudinal arch of the foot, that the interindividual differences are large but tend to decrease with age, and that the pressure ratio was slightly greater on the right foot than on the left foot. These authors reported large interindividual variations, in agreement with the $\mathrm{CV}$ presented herein. 
This study was conducted with 67 preschool children, most of whom were eutrophic. The characterization of our sample corroborates in part studies by Phethean and Nester (2012) in which body mass and the BMI of children 4-7 years of age showed a weak positive association with plantar pressure data $(r \leq 0.48, p<0.05)$, with no significant differences in plantar pressures between the boys and girls. These authors thus suggest that plantar pressure data do not require normalization to body weight or BMI, and can be applied for both boys and girls.

Other authors such as Dowling, Steele, and Baur (2004) and Filippin, Barbosa, Sacco, and Lobo da Costa (2007) assert that obese children (high BMI) who were older than our sample (age: $8.8 \pm 2.0$ and $9.6 \pm 0.7$ years) generate higher peak pressures. However, in their results, the continuing effect of the excessive mass of the children seemed to flatten the medial aspect of the foot. These children presented a developed medial plantar arch, while the preschoolers had significantly different arch volumes of the foot because their plantar arches were still developing (Chang, Hung, Wu, Chiu, \& Hsu, 2010).

In the postural photogrammetry evaluations, the authors found no reference for preschoolers in the literature. We only considered variables with acceptable inter-rater agreement, that is, an ICC index $>0.70$. None of the variables showed significant differences between the sexes, in disagreement with authors who reported biomechanical and neuromuscular differences between the sexes, such as Betts, Franks, Duckworth, and Burke (1980).

Örtqvist et al. (2011) evaluated healthy children aged 9-16 years and found that the reference values for the knee angle (mean, $13.5^{\circ}$ $\pm 1.9^{\circ}$ and $15.3^{\circ} \pm 2.8^{\circ}$ ) varied according to age and sex, and these values are similar to those we found for the $\mathrm{Q}$ angle. Lafond, Descarreaux, Normand, and Harrison (2007) evaluated the sagittal plane posture of children aged $4-12$ years and found significant sex-related differences in the parameters for the shoulder, pelvis, and knee. These differences may be related to the differences in the ages of the children in the studies. Studies that found sex-related differences included children older than our study sample.

Regarding the baropodometric data such as total surface area $\left(\mathrm{cm}^{2}\right)$, maximum pressure $\left(\mathrm{g} / \mathrm{cm}^{2}\right)$, and mean pressure $\left(\mathrm{g} / \mathrm{cm}^{2}\right)$, we found few studies with reference values for preschool children. In healthy children with a mean age of 10 years, Dowling et al. (2004) found higher plantar surface values than those found in the present study, in which the mean age of the children was 4.6 years. In the present study, sex did not influence the parameters measured, which is in agreement with the findings of Hennig, Staats, and Rosenbaum (1994).

Bertsch, Unger, Winkelmann, and Rosenbaum (2004) pointed out that during infancy, the fat pad present in the midfoot reduces the load applied on the plantar region, protecting the structures of the tarsal bones. A feature also indicated on the plantar pressure distribution in children is that because of the difference in foot size, pressure surges are considerably smaller in children, representing about one third of the value found in adults. Early analysis of plantar pressure distribution can reveal the interface between the plantar surface of the foot and posture, allowing postural monitoring (Sazonov, Fulk, Hill, Schutz, \& Browning, 2011).

The present study revealed a null correlation between surface symmetry and the symmetry of the foot morphology. These results suggest that the foot morphology in preschoolers cannot be evaluated through the baropodometry parameter of the foot surface.

Chen et al. (2010) evaluated footprints in healthy children of different ages, and the mean SAI in children aged 5 years was 1.05 , similar to the mean value that we obtained (0.75). According to Staheli, Chew, and Corbett (1987), during childhood, normal SAI values are between 0.70 and 1.35 , and the width of the calcaneus is 1.3 times higher than that of the isthmus. Therefore, the method of footprint analysis used in this study is adequate for diagnosis in preschool children (Staheli et al., 1987), and our values are within normal parameter values for the foot morphology in children. 
Asymmetries at such an early age can be caused by congenital etiologies such as torticollis, clubfoot, hip dislocation, and plagiocephaly caused by intrauterine position (Behrman et al., 2000; Nissinen et al., 1989). In childhood, the lower limbs exhibit alignment variations such as rotations and angular deformities, these variations being the result of normal growth and development, which are resolved in part without treatment (Sass \& Hassan, 2003). In preschool children, several studies have identified a high prevalence of postural asymmetries classified as physiological and non-structural that could be precursors of scoliosis (Juskeliene et al., 1996; Nissinen et al., 1989; Vercauteren et al., 1982). The children evaluated in this study are also in this age group, and the symmetry values for many of the parameters were less than $90 \%$, in agreement with the high prevalence of asymmetry found in the literature. A two-year prospective study with 7,609 children aged 6 months or younger showed that postural asymmetry persisted in $25 \%$ of the children (Boere-Boonekamp \& van der LindenKuiper, 2001).

According to Juskeliene et al. (1996), the three risk factors of postural asymmetry are childhood rickets, a high incidence of acute illness, and decreased levels of physical activity. According to Latalski et al. (2013), besides the relationship between physical activity and posture, they found also a relationship between family economic status and health status.

Although the level of physical activity in our sample was not formally assessed, the children clinically known to have no significant levels of physical activity or nutritional support because they were children with social risks who were entered in a neuromotor development program. Thus, the risks referred to by the authors correlated with the risk to which the study population was subjected. The embodiment of a physical activity and health education program, and a prospective control of these asymmetries is an important requirement for this group of children in order to prevent or reduce the risk of scoliosis and/or future structural asymmetries.

We therefore suggest that in addition to physical activity and nutritional counseling, guidance of children in this age group, as well as their families, should be provided regarding the use of footwear with adequate flexibility and without heels, the correct sleeping position with the appropriate pillow height and a mattress with the ideal density for their body mass, and the use of pacifiers and bottles at the right age. Furthermore, preschool children should be provided with motor and sensory experiences to the feet to stimulate arch formation. These strategies can minimize the appearance of biomechanical alterations related to postural imbalances.

The limitations of this study must be acknowledged. Measurements of posture and baropodometric parameters were not performed simultaneously, which might have contributed to the lack of correlation between some of the measurements. Nevertheless, baropodometry is suitable for measuring plantar pressure distribution, and its analysis is predictive of postural symmetry (Gurfinkel, Ivanenko YuP, Levik YuS, \& Babakova, 1995).

Postural analysis by performing photogrammetry also has its limitations. Poletto, Sato, Carnaz, Lobo da Costa, and Gil Coury (2007), indicated differences in results even when evaluating parameters obtained from the same photograph, such as the symmetry of the knee evaluated in the frontal plane, and that pictures obtained (e.g., right and left knee profile) could influence the outcome of symmetry. The observation made by the authors can justify the fact that most of the parameters of postural symmetry showed no significant correlation with any of the parameters of the static baropodometric symmetry.

Another limitation is the very large interindividual differences with high CV mainly in the posture evaluation by photogrammetry $(\mathrm{CV}=5.9 \%-1999 \%)$, even though Santos, Silva, Sanada, and Alves (2009) referred to this as a viable method and has the potential to generate baseline data on postural alignment in children.

According to Filippin et al. (2007), the variability of the measurements in developing children is a concern. For the variables of peak, mean, and maximum pressures during walking, the authors found CV of $16 \%-41 \%$. In this study, 
higher CVs were found for the baropodometric parameters, ranging from $29 \%$ to $82 \%$. In a study that assessed the ratio of anteroposterior foot pressure in children aged 3.5-6.5 years, the interindividual differences were great but tended to decrease with age (Matsuda \& Demura, 2013).

Postural asymmetries in childhood have a multifactorial etiology. Although no consensus has been reached regarding its definition, classifications, and nomenclature, and data regarding its natural course are scarce, there is a great need for systematic management of asymmetry in infancy (van Vlimmeren et al., 2004). Future studies should be conducted with a larger sample size to allow the establishment of age categories in a prospective study to follow up asymmetry postures throughout early childhood by using the load and foot morphology assessment methods used in this study.

\section{CONCLUSIONS}

Thus, we conclude that children in the age group studied had a high frequency of postural asymmetries, especially in the knee, without any difference between the sexes. For this reason, although asymmetries are a common feature of development, they are poorly studied. While most asymmetries are spontaneously resolved, early postural assessment can support the detection and intervention of disorders of the developing musculoskeletal system and prevent locomotor system adaptations to alter the biomechanical conditions of the individual.

Therefore, prospective studies should be conducted with children to monitor these asymmetries, their causes, and correlations for the prevention of structural asymmetries such as idiopathic scoliosis. Postural education programs should be implemented early in children's lives.

Moreover, these results provide the basis for a more accurate assessment of postural changes and deformities in pediatric feet through baropodometric and evaluation methods for foot morphology that are suitable for this purpose. In addition, another method for assessing body composition should then be investigated to demonstrate a good correlation with foot load distribution parameters.
Acknowledgment:

Nothing to declare.

Conflict of interest:

Nothing to declare.

Funding:

Nothing to declare.

\section{REFERENCES}

Behrman, R. E., Kliegman, R., \& Jenson, B. (2000). Nelson Textbook of Pediatrics (16th ed.). Philadelphia: WB Saunders Co.

Bertsch, C., Unger, H., Winkelmann, W., \& Rosenbaum, D. (2004). Evaluation of early walking patterns from plantar pressure distribution measurements. First year results of 42 children. Gait \& Posture, 19(3), 235-242. http://doi.org/10.1016/S0966-6362(03)00064$\mathrm{X}$

Betts, R. P., Franks, C. I., Duckworth, T., \& Burke, J. (1980). Static and dynamic foot-pressure measurements in clinical orthopaedics. Medical \& Biological Engineering \& Computing, 18(5), 674-684.

Boere-Boonekamp, M. M., \& van der Linden-Kuiper, L. T. (2001). Positional preference: prevalence in infants and follow-up after two years. Pediatrics, 107(2), 339-343.

Bruner, E., Mantini, S., Guerrini, V., Ciccarelli, A., Giombini, A., Borrione, P., ... Ripani, M. (2009). Preliminary shape analysis of the outline of the baropodometric foot: patterns of covariation, allometry, sex and age differences, and loading variations. The Journal of Sports Medicine and Physical Fitness, 49(3), 246-254.

Chang, Y. W., Hung, W., Wu, H., Chiu, Y. C., \& Hsu, H. C. (2010). Measurements of foot arch in standing, level walking, vertical jump and sprint start. International Journal of Sport and Exercise Science, 2(2), 35-42.

Chen, K.-C., Yeh, C.-J., Kuo, J.-F., Hsieh, C.-L., Yang, S.-F., \& Wang, C.-H. (2010). Footprint analysis of flatfoot in preschool-aged children. European Journal of Pediatrics, 170(5), 611-617. http://doi.org/10.1007/s00431-010-1330-4

Cheng, J. C., \& Au, A. W. (1994). Infantile torticollis: a review of 624 cases. Journal of Pediatric Orthopedics, 14(6), 802-808.

Clark, N. C. (2001). Functional performance testing following knee ligament injury. Physical Therapy in Sport, 2(2), 91-105. http://doi.org/10.1054/ptsp.2001.0035

Cohen, J. (1994). The earth is round $(\mathrm{p}<.05)$. American Psychologist, 49(12), 997-1003. http://doi.org/10.1037/0003-066X.49.12.997

Dowling, A. M., Steele, J. R., \& Baur, L. A. (2004). What are the effects of obesity in children on 
plantar pressure distributions? International Journal of Obesity, 28(11), 1514-1519. http://doi.org/10.1038/sj.ijo.0802729

Ferreira, E. A. G., Duarte, M., Maldonado, E. P., Burke, T. N., \& Marques, A. P. (2010). Postural assessment software (PAS/SAPO): validation and reliabiliy. Clinics, 65(7), 675-681. http://doi.org/10.1590/S180759322010000700005

Filippin, N. T., Barbosa, V. L. P., Sacco, I. C. N., \& Lobo da Costa, P. H. (2007). Efeitos da obesidade na distribuição de pressão plantar em crianças. Brazilian Journal of Physical Therapy, 11(6), 495-501. 35552007000600012

Gurfinkel, V. S., Ivanenko YuP, null, Levik YuS, null, \& Babakova, I. A. (1995). Kinesthetic reference for human orthograde posture. Neuroscience, 68(1), 229-243.

Hennig, E. M., Staats, A., \& Rosenbaum, D. (1994). Plantar pressure distribution patterns of young school children in comparison to adults. Foot \& Ankle International, 15(1), 35-40.

Iunes, D. H., Castro, F. A., Salgado, H. S., Moura, I. C., Oliveira, A. S., \& Bevilaqua-Grossi, D. (2005). Confiabilidade intra e interexaminadores e repetibilidade da avaliação postural pela fotogrametria. Brazilian Journal of Physical Therapy, 9(3), 327-334.

Juskeliene, V., Magnus, P., Bakketeig, L. S., Dailidiene, N., \& Jurkuvenas, V. (1996). Prevalence and risk factors for asymmetric posture in preschool children aged 6-7 years. International Journal of Epidemiology, 25(5), 1053-1059.

Kellis, E. (2001). Plantar pressure distribution during barefoot standing, walking and landing in preschool boys. Gait \& Posture, 14(2), 92-97.

Kratěnová, J., ŽEjglicová, K., Malý, M., \& Filipová, V. (2007). Prevalence and Risk Factors of Poor Posture in School Children in the Czech Republic. Journal of School Health, 77(3), 131137. http://doi.org/10.1111/j.17461561.2007.00182.x

Lafond, D., Descarreaux, M., Normand, M. C., \& Harrison, D. E. (2007). Postural development in school children: a cross-sectional study. Chiropractic \& Osteopathy, 15, 1. http://doi.org/10.1186/1746-1340-15-1

Latalski, M., Bylina, J., Fatyga, M., Repko, M., Filipovic, M., Jarosz, M. J., ... Trzpis, T. (2013). Risk factors of postural defects in children at school age. Annals of Agricultural and Environmental Medicine: AAEM, 20(3), 583587.

Matsuda, S., \& Demura, S. (2013). Age-related, interindividual, and right/left differences in anterior-posterior foot pressure ratio in preschool children. Journal of Physiological Anthropology, 32, http://doi.org/10.1186/1880-6805-32-8
McMaster, M. J. (1983). Infantile idiopathic scoliosis: can it be prevented? The Journal of Bone and Joint Surgery. British Volume, 65(5), 612-617.

Nissinen, M., Heliövaara, M., Tallroth, K., \& Poussa, M. (1989). Trunk asymmetry and scoliosis: Anthropometric measurements in prepuberal school children. Acta Pædiatrica, 78(5), 747-753. http://doi.org/10.1111/j.16512227.1989.tb11137.x

Örtqvist, M., Moström, E. B., Roos, E. M., Lundell, P., Janarv, P.-M., Werner, S., \& Broström, E. W. (2011). Reliability and reference values of two clinical measurements of dynamic and static knee position in healthy children. Knee Surgery, Sports Traumatology, Arthroscopy, 19(12), 2060-2066. http://doi.org/10.1007/s00167011-1542-9

Peskin, M., Spitzer, S., Peleg, T., \& Zalsman, G. (2011). [Nosology, assessment and diagnosis of psychiatric disorders in early childhood]. Harefuah, 150(4), 353-358, 419, 418.

Phethean, J., \& Nester, C. (2012). The influence of body weight, body mass index and gender on plantar pressures: results of a cross-sectional study of healthy children's feet. Gait \& Posture, $36(2)$, 287-290. http://doi.org/10.1016/j.gaitpost.2012.03.012

Rochat, P., \& Goubet, N. (1995). Development of sitting and reaching in 5- to 6-month-old infants. Infant Behavior and Development, 18(1), 53-68. http://doi.org/10.1016/0163-6383(95)90007-1

Santos, M. M., Silva, M. P. C., Sanada, L. S., \& Alves, C. R. J. (2009). Photogrammetric postural analysis on healthy seven to ten-year-old children: interrater reliability. Brazilian Journal of Physical Therapy, 13(4), 350-355. http://doi.org/10.1590/S141335552009005000047

Sass, P., \& Hassan, G. (2003). Lower extremity abnormalities in children. American Family Physician, 68(3), 461-468.

Sazonov, E. S., Fulk, G., Hill, J., Schutz, Y., \& Browning, R. (2011). Monitoring of posture allocations and activities by a shoe-based wearable sensor. IEEE Transactions on BioMedical Engineering, 58(4), 983-990. http://doi.org/10.1109/TBME.2010.2046738

Staheli, L. T., Chew, D. E., \& Corbett, M. (1987). The longitudinal arch. A survey of eight hundred and eighty-two feet in normal children and adults. The Journal of Bone and Joint Surgery. American Volume, 69(3), 426-428.

St John, D., Mulliken, J. B., Kaban, L. B., \& Padwa, B. L. (2002). Anthropometric analysis of mandibular asymmetry in infants with deformational posterior plagiocephaly. Journal of Oral and Maxillofacial Surgery: Official Journal of the American Association of Oral and Maxillofacial Surgeons, 60(8), 873-877.

Stebbins, J. A., Harrington, M. E., Giacomozzi, C., Thompson, N., Zavatsky, A., \& Theologis, T. N. (2005). Assessment of sub-division of plantar 
70 | PO Almeida, GFG Prudente, FE de Sá, LAO Lima, FR Jesus-Moraleida, KV Viana-Cardoso

pressure measurement in children. Gait \& Posture, 22(4), 372-376. http://doi.org/10.1016/j.gaitpost.2004.10.004

Van Maanen, C. J., Zonnenberg, A. J., Elvers, J. W., \& Oostendorp, R. A. (1996). Intra/interrater reliability of measurements on body posture photographs. Cranio: The Journal of Craniomandibular Practice, 14(4), 326-331.

van Vlimmeren, L. A., Helders, P. J. M., van Adrichem, L. N. A., \& Engelbert, R. H. H. (2004). Diagnostic strategies for the evaluation of asymmetry in infancy-a review. European Journal of Pediatrics, 163(4-5), 185-191. http://doi.org/10.1007/s00431-004-1412-2

Vercauteren, M., Van Beneden, M., Verplaetse, R., Croene, P., Uyttendaele, D., \& Verdonk, R. (1982). Trunk asymmetries in a Belgian school population. Spine, 7(6), 555-562.

Watson, A. W., \& Mac Donncha, C. (2000). A reliable technique for the assessment of posture: assessment criteria for aspects of posture. The Journal of Sports Medicine and Physical Fitness, 40(3), 260-270. 